\title{
Influência do tipo de argila no processo de solidificação/ estabilização de lodo têxtil
}

\section{(Influence of clay type in the solidification stabilization process of textile sludge)}

\author{
P. H.S. Almeida, J. de M. Franco, C.R. G. Tavares \\ Universidade Estadual de Maringá - UEM, Maringá, PR 87020-900 \\ phsoal@yahoo.com.br
}

\begin{abstract}
Resumo
As argilas estão entre as mais importantes matérias-primas devido as suas múltiplas funções industriais. No caso especial da indústria de cerâmica vermelha, as argilas têm ampla utilidade, sendo o principal produto para a fabricação de telhas e blocos cerâmicos, que podem ser incorporados com resíduos industriais. Portanto, o objetivo deste trabalho foi estudar a influencia dos diferentes tipos de argilas na qualidade dos blocos cerâmicos de vedação, incorporados com lodo têxtil, por meio do processo de solidificação/ estabilização. Avaliou-se a incorporação do lodo têxtil em 5 tipos de argilas, coletadas na região norte do Paraná, e realizou-se uma análise qualitativa dos blocos cerâmicos, com composição de $15 \%$ de resíduo têxtil, em função de suas características, estabelecidas nas normas da Associação Brasileira de Normas Técnicas. O resíduo utilizado foi proveniente de 12 indústrias têxteis de Maringá, PR. Inicialmente foi feita uma caracterização do lodo e das argilas. Os blocos cerâmicos foram fabricados em escala reduzida e submetidos a testes de resistência a compressão, lixiviação, solubilização e absorção de água, de acordo com as respectivas normas. Verificou-se nas condições estudadas que os blocos cerâmicos não apresentaram lixiviação nem solubilização. Portanto, o processo de solidificação/estabilização foi capaz de imobilizar de forma eficaz, os metais presentes no resíduo têxtil, mostrando-se como um promissor processo de minimização do impacto ambiental.
\end{abstract}

Palavras-chave: lodo, argila, bloco cerâmico, solidificação/estabilização.

\begin{abstract}
Clays are among the most important raw materials due to their numerous industrial functions. In the special case of the red ceramic industry, the clays have wide utility, being the main product for the manufacture of ceramic tiles and blocks, which can be incorporated with industrial waste. This way, the aim of this work was to study the influence of the different types of clays on the quality of sealing ceramic blocks, with incorporated textile mud through the process of solidification/stabilization. It was evaluated the incorporation of textile mud in 5 types of clays which were collected in northern Paraná, Brazil, and a qualitative analysis of ceramic blocks with $15 \%$ of textile waste in its composition was performed, in terms of its characteristics, set in the standards of Brazilian Association of Technical Standards. The used residues were provided by 12 textile industries of Maringá, PR, Brazil. Firstly, the characterization of mud and clays was carried out. The ceramic blocks were manufactured in small scale and tested for resistance to compression, leaching, solubilization and water absorption, according to their standards methods. The blocks presented no leaching or solubilization under the studied conditions. Therefore, the manufacture of ceramic blocks has been able to effectively immobilize the metals present in textile waste, showing to be a promising process to minimize environmental impact. Keywords: mud, clay, ceramic block, solidification/stabilization.
\end{abstract}

\section{INTRODUÇÃO}

As indústrias de processamento têxtil são importantes segmentos econômicos e sociais no Brasil e no mundo. Com o desenvolvimento tecnológico, o número dessas indústrias vem crescendo a cada dia e com elas a quantidade de lodos e resíduos industriais. Com o esgotamento das reservas de matérias-primas, e a crescente e progressiva implantação de novas e exigentes diretrizes na gestão de lodos e resíduos, fazse necessário o desenvolvimento de métodos de tratamento alternativos e eficazes, em substituição ao simples descarte desses em aterros sanitários.

A incorporação de resíduos industriais em matrizes sólidas, tais como cerâmicas e argamassas de cimento, produzindo-se materiais aplicáveis na construção civil, consiste numa alternativa de disposição ou tratamento do resíduo. A argila pode ser moldada facilmente, pela sua alta plasticidade, apresentando resistência estrutural e estabilidade aos seus constituintes da massa, após a queima em alta temperatura.

Em geral, as argilas são materiais heterogêneos, cujas características dependem da sua formação geológica e 
da localização da extração. Para a utilização das argilas em processos industriais é importante e indispensável uma identificação completa do tipo de argila e de suas propriedades, para estabelecer quais as formulações e condições de processamento são mais adequadas para se obter produtos com as propriedades finais desejadas [1].

A técnica de solidificação/estabilização é umas das formas de tratamento e disposição dos resíduos industriais. Este processo possibilita melhorar as características físicas do resíduo, diminuir a área superficial ou limitar a solubilidade dos constituintes perigosos [2]. O processo consiste no encapsulamento do resíduo junto à matriz sólida, para que este se mantenha fixado na massa, em conseqüência da fusão com queima ou cimentação com aditivos quimicamente reativos entre os materiais envolvidos, oxidando a matéria orgânica, destruindo qualquer organismo patogênico durante o processo de queima e evitando a lixiviação ou solubilização dos elementos constituintes do resíduo, considerados nocivos ao ambiente. Os resultados dessas interações são sólidos não-perigosos ou menos perigosos que o resíduo original [3]. A vantagem desta técnica é que ela apresenta a possibilidade de reaproveitamento do solidificado como material de construção, além das exigências simples de processamento e o uso de equipamentos prontamente disponíveis nas indústrias construtoras [4].

Esse trabalho tem por objetivo estudar a influência dos tipos de argilas na produção de blocos cerâmicos de vedação a partir do processo de solidificação/estabilização de lodo têxtil. A incorporação do lodo têxtil em matrizes sólidas foi realizada na proporção de $15 \%$ de m relação à argila, produzindo-se materiais aplicáveis na construção civil.

\section{MATERIAIS E MÉTODOS}

As matrizes sólidas utilizadas foram argilas provenientes de 5 cerâmicas localizadas na região do Médio-Baixo Rio Ivaí, PR, abrangendo as cidades de Japurá (2 jazidas), S. Carlos do Ivaí (2 jazidas) e Floresta (1 jazida) que se destacam como grandes produtores de cerâmica vermelha na região norte do estado do Paraná. A mesma foi caracterizada quanto ao teor de umidade e matéria orgânica total [5], pH [6], análise granulométrica [7], limite de plasticidade [8], limite de liquidez [9], índice de plasticidade [8] e massa específica (método do picnômetro).

O resíduo têxtil (lodo) utilizado neste trabalho foi proveniente de 12 lavanderias industriais situadas na região de Maringá, PR, e é gerado no processo de tratamento de efluentes, na fase de floculação/coagulação. Estes resíduos foram coletados em estado semisseco e, misturados e homogeneizados em quantidades iguais, determinadas em porcentagem de massa seca. O lodo foi secado antes de ser adicionado à argila. $\mathrm{O}$ lodo foi caracterizado quanto aos seguintes parâmetros: teor de umidade e matéria orgânica total [5], massa específica (método do picnômetro, usando água), $\mathrm{pH}$ [10], análise química (relacionada aos metais por meio da extração ou digestão ácida, com ácido fluorídrico e água régia) e quanto suas características tóxicas relacionadas aos procedimentos de lixiviação [11] e solubilização [12]. Para determinação dos elementos químicos dos extratos lixiviados e solubilizados, bem como do extrato da digestão ácida foi utilizado o espectrofotômetro de absorção atômica modelo SpectrAA 50B da Varian.

A argila e o resíduo foram triturados em moinho com barras cilíndricas, passando em seguida pela peneira $10 \mathrm{com}$ malha de $2,5 \mathrm{~mm}$, para posterior mistura, em porcentagem de massa seca, e homogeneização. O peneiramento foi necessário para que partículas sólidas não obstruíssem a boquilha da extrusora de bancada, comprometendo a qualidade dos blocos. Após a mistura e homogeneização, a massa foi transferida para recipiente de amassamento, adicionando-se água de forma gradativa, até formar uma massa consistente com plasticidade a ponto de abastecer uma extrusora de laboratório Gerenski MVIG-05. A boquilha de saída da extrusora da o formato ao bloco cerâmico de vedação, um tijolo de seis furos com $1 / 3$ das dimensões do encontrado no mercado, ou seja, paredes e septos de $2,5 \mathrm{~mm}$, largura de $33 \mathrm{~mm}$, altura de $50 \mathrm{~mm}$ e comprimento de 67 mm. Após a confecção, os blocos cerâmicos eram secos em temperatura ambiente em local fechado e ventilado, durante 7 dias, para evaporação da água absorvida. Após a secagem eram queimados no forno de uma cerâmica localizada na cidade de Floresta-PR, a $850{ }^{\circ} \mathrm{C}$ durante $72 \mathrm{~h}$, garantindo as condições de queima de um processo industrial. $\mathrm{O}$ resfriamento dos blocos ocorreu de forma natural por cinco dias, até alcançar a temperatura ambiente para o recolhimento do material pronto para análise.

Os ensaios de resistência à compressão e absorção de água foram realizados conforme procedimento descrito na norma NBR 15270-3:2005 da ABNT [13]. A caracterização dos blocos cerâmicos referentes às análises de metais foi feita por meio da determinação de suas características tóxicas, relacionadas aos procedimentos de lixiviação [11] e solubilização [12].

\section{RESULTADOS E DISCUSSÃO}

\section{Caracterização do lodo têxtil}

O lodo foi caracterizado quanto ao teor de umidade e matéria orgânica total, massa específica, $\mathrm{pH}$, concentração de metais e quanto suas características tóxicas relacionadas aos procedimentos de lixiviação [11] e solubilização [12]. A Tabela I apresenta os resultados da caracterização do lodo, bem como os resultados das análises de presença de metais.

Por meio da análise de caracterização do resíduo, observou-se que o lodo da indústria têxtil possui uma grande quantidade de alumínio, ferro, manganês e sódio. Provavelmente estes metais são provenientes do processo de tratamento de efluentes têxteis que se fixam no resíduo sólido. Na maioria das indústrias, o processo de tratamento é feito por coagulação/floculação, utilizando sulfato de alumínio e cloreto férrico como agentes coagulantes. Dentre os metais analisados, prata, bário, cádmio, arsênio, mercúrio e selênio não foram detectados no resíduo em questão. 
Tabela I - Características do resíduo têxtil (lodo). [Table I-Characteristics of textile waste (mud).]

\begin{tabular}{lc}
\hline \multicolumn{1}{c}{ Parâmetros } & Lodo \\
\hline Aspecto & Pastoso \\
$\mathrm{pH}$ & 7,8 \\
Massa específica $\left({\left.\mathrm{g} . \mathrm{cm}^{-3}\right)}^{-1}\right)$ & 1,95 \\
Matéria orgânica total (\%) (base seca) & 41,0 \\
Teor de umidade (\%) & 21,5 \\
Metais (mg.kg-1) & \\
$\mathrm{Al}$ & $62.966,7$ \\
$\mathrm{~Pb}$ & 174,7 \\
$\mathrm{Cu}$ & 287,5 \\
$\mathrm{Cr}$ & 195,0 \\
$\mathrm{Fe}$ & $35.172,4$ \\
$\mathrm{Mn}$ & $1.106,1$ \\
$\mathrm{Na}$ & $33.275,3$ \\
$\mathrm{Zn}$ & 294,4 \\
$\mathrm{Ag}$ & n.d \\
$\mathrm{Ba}$ & n.d \\
$\mathrm{Cd}$ & n.d \\
$\mathrm{As}$ & n.d \\
$\mathrm{Ba}$ & n.d \\
$\mathrm{Hg}$ & n.d \\
$\mathrm{Se}$ & n.d \\
\hline
\end{tabular}

n.d: não detectado.

A matéria orgânica exerce um papel importante na química de argilas. Capacidade de troca catiônica (é determinada pelas substituições catiônicas na estrutura dos argilominerais) e pH são propriedades das argilas associadas à matéria orgânica. O conteúdo de matéria orgânica, assim como a umidade, são parâmetros importantes que podem influenciar na qualidade final dos blocos cerâmicos. Observou-se na análise do lodo, (Tabela I), uma grande quantidade de matéria orgânica, presente no lodo têxtil (41\%), que pode ocasionar a formação de poros ou blocos com baixa densidade, o que pode influenciar na resistência e qualidade dos blocos cerâmicos.

As Tabelas II e III apresentam os resultados das análises de caracterização tóxica do lodo têxtil, relacionadas aos ensaios de lixiviação [11] e solubilização [12], respectivamente.

A análise do extrato lixiviado permite avaliar o grau de imobilização dos contaminantes quando em contato com soluções aquosas, que podem ser encontradas em um aterro [14].

Analisando o extrato lixiviado, verificou-se que os metais relacionados na norma NBR 10004:2004 (anexo F), não foram detectados. Dessa forma, o lodo têxtil pode ser classificado como um resíduo de classe II, ou não perigoso.

A realização da análise do extrato solubilizado tem como objetivo diferenciar os resíduos classificados na norma NBR 10004:2004 (anexo G) da ABNT, como classe
Tabela II - Características tóxicas do resíduo (procedimento de lixiviação).

[Table II - Toxic characteristics of waste (leaching procedure).]

\begin{tabular}{lcc}
\hline Metais & $\begin{array}{c}\text { Concentração } \\
\left(\mathrm{mg} . \mathrm{L}^{-1}\right)\end{array}$ & $\begin{array}{c}\text { Lim. Máx. }\left(\mathrm{mg} . \mathrm{L}^{-1}\right) \\
\text { NBR 10004:2004 (Anexo F) }\end{array}$ \\
\hline Arsênio & n.d & 1,0 \\
Bário & n.d & 70,0 \\
Cádmio & n.d & 0,5 \\
Chumbo & n.d & 1,0 \\
Cromo & n.d & 5,0 \\
Mercúrio & n.d & 0,1 \\
Prata & n.d & 5,0 \\
Selênio & n.d & 5,0 \\
\hline n.d: não detectado. & &
\end{tabular}

Tabela III - Características tóxicas do resíduo (procedimento de solubilização).

[Table III - Toxic characteristics of waste (solubilization procedure).]

\begin{tabular}{lcc}
\hline Metais & $\begin{array}{c}\text { Concentração } \\
\left(\mathrm{mg} . \mathrm{L}^{-1}\right)\end{array}$ & $\begin{array}{c}\text { Lim. Máx. }\left(\mathrm{mg} \mathrm{L}^{-1}\right) \\
\text { NBR 10004:2004 (Anexo G) }\end{array}$ \\
\hline Arsênio & n.d & 0,01 \\
Bário & n.d & 0,7 \\
Cádmio & n.d & 0,005 \\
Chumbo & 0,07 & 0,01 \\
Cromo & 0,05 & 0,05 \\
Mercúrio & n.d & 0,001 \\
Prata & n.d & 0,05 \\
Selênio & n.d & 0,01 \\
Alumínio & 0,3 & 0,2 \\
Cobre & n.d & 2,0 \\
Ferro & n.d & 0,3 \\
Zinco & 0,06 & 5,0 \\
Manganês & 4,2 & 0,1 \\
Sódio & 285,3 & 200,0 \\
\hline
\end{tabular}

n.d: $n \tilde{a} o$ detectado.

II A - não inertes - e classe II B - inertes.

No lodo em questão, as concentrações dos metais presentes no extrato solubilizado [12], mostram que, alumínio, chumbo, manganês e sódio, apresentaram valores de concentração acima dos limites estabelecidos pela referida norma, o que leva a classificá-lo como um resíduo classe IIA, ou não inerte.

Os resultados de caracterização do lodo mostram que este resíduo não pode ser descartado em aterros comuns, havendo necessidade de um processo de tratamento adequado, possibilitando assim a sua reutilização como matéria-prima secundária, ou então ser disposto em aterros de resíduos industriais. 


\section{Caracterização das argilas}

A Tabela IV apresenta os resultados das análises de caracterização das argilas utilizadas para a fabricação dos blocos cerâmicos. Foram preparadas amostras de acordo com as normas estabelecidas para a determinação do $\mathrm{pH}$, massa específica, matéria orgânica total e umidade.

As argilas utilizadas no presente trabalho foram coletadas em jazidas encontradas normalmente em várzeas dos rios da região norte do Paraná, onde predominam rochas sedimentares, folhetos, arenitos e calcários.

$\mathrm{O} \mathrm{pH}$ de argilas é provavelmente uma das medidas mais informativas que pode ser feita para determinar as suas características, e indica muito mais do que simplesmente sua acidez ou basicidade. $\mathrm{O}$ valor do $\mathrm{pH}$ determina a disponibilidade dos minerais contidos ou adicionados ao solo. Os minerais são responsáveis pela capacidade de troca de íons que ocorrem na estrutura cristalina das argilas, influenciando diretamente sobre as suas propriedades físicoquímicas, modificando a plasticidade de argilas.

A plasticidade de uma argila depende basicamente de sua finura, presença de matéria orgânica e água. Conforme o teor de água adicionado, altera-se a plasticidade e as características do bloco produzido. $\mathrm{O}$ pH influenciará no processo de floculação/dispersão do sistema, pela alteração das cargas nas arestas dos argilominerais, influenciando assim o processamento do bloco. Os valores de $\mathrm{pH}$ das argilas analisadas foram semelhantes, em torno de 5. Geralmente valores de $\mathrm{pH}$ do solo de 4 a 6 , indicam a presença dos minerais: hematita $\left(\mathrm{Fe}_{2} \mathrm{O}_{3}\right)$ e alumina $\left(\mathrm{Al}_{2} \mathrm{O}_{3}\right)$, que influenciam muito o comportamento de plasticidade das argilas analisadas, bem como a capacidade de retenção de água no bloco cerâmico [15].

A matéria orgânica, assim como a umidade, são parâmetros importantes que podem influenciar na qualidade final dos blocos cerâmicos. Durante o processo de queima dos blocos, a matéria orgânica é volatilizada, ocasionando a formação de poros que diminuem a estabilidade estrutural da massa cerâmica, reduzindo substancialmente a resistência mecânica do bloco.

A Tabela V apresenta as distribuições granulométricas das argilas estudadas.

As amostras apresentam diferentes distribuições granulométricas com exceção das amostras 1 e 4, oriundas da mesma jazida (S. Carlos do Ivaí), que apresentam a mesma granulometria. Pode-se observar que a fração argila das amostras analisadas variou de $42 \%$ para as amostras 1 e 4 a 58\% para a amostra 3 . As amostras apresentam fração argila acima do mínimo indicado para massas cerâmicas visando a produção de blocos cerâmicos (fração argila entre

Tabela IV - Caracterização das argilas.

[Table IV - Characterization of clay.]

\begin{tabular}{lccccc}
\hline Parâmetros & Argila 1 & Argila 2 & Argila 3 & Argila 4 & Argila 5 \\
\hline $\mathrm{pH}$ & 5,49 & 5,44 & 5,45 & 5,54 & 5,35 \\
Massa específica $\left({\left.\mathrm{g} . \mathrm{cm}^{-3}\right)}^{2,81}\right.$ & 2,70 & 2,78 & 2,79 & 2,73 \\
M. O. total $(\%)$ & 7,03 & 6,36 & 6,22 & 7,05 & 7,71 \\
Teor de umidade (\%) & 4,78 & 4,62 & 4,42 & 4,80 & 5,43 \\
\hline
\end{tabular}

Tabela V - Análise granulométrica das argilas.

[Table V - Size analysis of clays.]

\begin{tabular}{ccccc}
\hline $\begin{array}{c}\text { Amostras de } \\
\text { argila bruta }\end{array}$ & $\begin{array}{c}\text { Argila }(\%) \\
\text { (menor que } 0,002 \mathrm{~mm})\end{array}$ & $\begin{array}{c}\text { Silte }(\%) \\
(\text { entre } 0,06 \mathrm{e} 0,002 \mathrm{~mm})\end{array}$ & $\begin{array}{c}\text { Areia fina }(\%) \\
(\text { entre } 0,24 \mathrm{e} 0,06 \mathrm{~mm})\end{array}$ & $\begin{array}{c}\text { Areia grossa (\%) } \\
(\text { entre 4,8 e } 1,0 \mathrm{~mm})\end{array}$ \\
\hline 1 & 42 & 32 & 26 & 0 \\
2 & 46 & 47 & 7 & 0 \\
3 & 58 & 23 & 15 & 4 \\
4 & 42 & 32 & 26 & 0 \\
5 & 43 & 20 & 32 & 5 \\
\hline
\end{tabular}

Tabela VI - Limites de consistência das argilas.

[Table VI - Consistency limits of clays.]

\begin{tabular}{lccccc}
\hline \multicolumn{1}{c}{ Parâmetros } & Argila 1 & Argila 2 & Argila 3 & Argila 4 & Argila 5 \\
\hline Limite de Plasticidade - LP (\%) & 26 & 29 & 24 & 21 & 18 \\
Limite de Liquidez - LL (\%) & 52 & 50 & 60 & 51 & 43 \\
Índice de Plasticidade - IP (\%) & 26 & 21 & 36 & 30 & 25 \\
\hline
\end{tabular}


20 e $30 \%$ ) [16].

Para a produção de blocos cerâmicos de boa qualidade, uma massa cerâmica não pode ser constituída apenas por argila. Ela é formulada contendo materiais de diferentes granulometrias, sendo a fração mais "fina" associada à argila (tamanho dos grãos: menor que $2 \mu \mathrm{m}, 0,002 \mathrm{~mm}$ ) e as demais ("mais grosseira") relacionadas ao silte $(0,002 \mathrm{a}$ $0,06 \mathrm{~mm})$, areia fina $(0,06$ a $0,24 \mathrm{~mm})$ e areia grossa $(1,0$ a 4,8 mm). O estudo de granulometria (estudo do tamanho dos grãos) para a classificação do solo é realizado segundo a norma NBR 7181:1984 da ABNT, e possibilita melhorar as propriedades do produto final, no caso, o bloco cerâmico.

As amostras de argila utilizadas apresentam características físicas apropriadas para produção de blocos cerâmicos, visto que, por meio da análise granulométrica apresentada na Tabela V, verificou-se que grande parte da composição da argila bruta (> 40\%) refere-se à fração argila, ou seja, trata-se de um material com alta capacidade de coesão, após o umedecimento adequado, contendo principalmente partículas da fração argila e silte, que são preponderantes para formação de rigidez durante a queima em forno.

Consistência é o termo usado para designar as manifestações das forças físicas de coesão entre partículas do solo e de adesão entre as partículas e outros materiais, conforme variação do grau de umidade. A Tabela VI apresenta os resultados referentes à consistência das argilas, representada pelo limite de plasticidade (LP), limite de liquidez (LL) e índice de plasticidade (IP).

A plasticidade das argilas é uma propriedade de grande interesse da indústria cerâmica. Plasticidade é a propriedade que um sistema possui de se deformar pela aplicação de uma força e de manter essa deformação quando a força aplicada é retirada. Em argilas, é essencialmente resultante das forças de atração entre partículas de argilominerais (minerais contidos na argila) e a ação lubrificante da água entre essas partículas. As argilas estudadas no presente trabalho podem ser consideradas materiais de alta plasticidade (LP > 15\%), ou seja, proporcionam excelente moldagem dos blocos de forma a adquirir alta densidade durante a produção por meio de extrusão. Analisando os valores do limite de plasticidade das argilas (Tabela VI), verificou-se que a plasticidade das argilas não variou significativamente, sendo a argila 5 a menos plástica, e a argila 2 a mais plástica. Assim, pode-se inferir que a argila 2 é melhor que a argila 5 em relação a facilidade de moldagem dos blocos cerâmicos.

O limite de liquidez (LL) das argilas variou de 43 a $60 \%$, enquanto o índice de plasticidade situou-se entre 21 e $36 \%$. No caso específico da tecnologia cerâmica, para moldagem de blocos cerâmicos por extrusão, a faixas de limite de liquidez (LL) e índice de plasticidade (IP), recomendadas para argilas plásticas, correspondem a: LL variando de $26,50 \%$ a $71,60 \%$ e IP variando de $4,00 \%$ a $47,70 \%$. Assim, as argilas utilizadas no presente trabalho são indicadas para a fabricação de blocos cerâmicos por meio de extrusão [17]. Verificou-se limites de liquidez (LL) superiores a $50 \%$, que indicam que estas argilas apresentam uma alta compressibilidade, tornando a massa cerâmica mais densa durante a extrusão, exceção feita à argila 5, que apresentou limite de liquidez de $43 \%$. Assim, nos blocos fabricados com a argila 5 podem ocorrer mais facilmente o surgimento de fissuras superficiais, aparecimento de trincas e deformações, em virtude de sua microestrutura apresentar menor coesão.

Foi comprovado que, na medida em que aumenta o conteúdo de argila do solo, aumentam também os valores do índice de plasticidade [18]; desta forma, quanto maior é a relação da superfície total das partículas de argila em relação ao seu volume, maior é o número de moléculas de água capaz de absorver e, por conseguinte, serão mais elevados os valores dos limites de liquidez. A argila 3 apresentou maior índice de plasticidade (IP) e limite de liquidez (LL), 36 e $60 \%$ respectivamente, decorrente da maior quantidade de argila presente na amostra (58\%, dado da Tabela V). Assim, das massas cerâmicas analisadas, a argila 3 é a mais indicada para a produção de blocos cerâmicos.

\section{Caracterização dos blocos cerâmicos}

A caracterização dos blocos cerâmicos foi realizada por meio de ensaios de retração, absorção de água, análise de metais e resistência mecânica das peças. A caracterização permitiu também estimar as argilas adequadas ou não para a produção de blocos cerâmicos.

Tabela VII - Resistência à compressão dos blocos cerâmicos.

[Table VII - Resistance to compression of the ceramic blocks.]

\begin{tabular}{lccccc}
\hline Identificação & Bloco 1 & Bloco 2 & Bloco 3 & Bloco 4 & Bloco 5 \\
\hline Resistência à Compressão (MPa) & 1,50 & 2,00 & 2,10 & 1,50 & 1,00 \\
Desvio Padrão & 0,24 & 0,30 & 0,38 & 0,18 & 0,12 \\
\hline
\end{tabular}

Tabela VIII - Absorção de água dos blocos cerâmicos.

[Table VIII - Water absorption of the ceramic blocks.]

\begin{tabular}{lccccc}
\hline Identificação & Bloco 1 & Bloco 2 & Bloco 3 & Bloco 4 & Bloco 5 \\
\hline Absorção de água (\%) & 18,41 & 19,34 & 19,79 & 18,50 & 18,11 \\
Desvio Padrão & 0,23 & 0,62 & 0,39 & 0,23 & 0,25 \\
\hline
\end{tabular}


Tabela IX - Concentração de metais do extrato lixiviado dos blocos cerâmicos.

[Table IX - Concentration of metals in leachate extract of ceramic blocks.]

\begin{tabular}{lcccccc}
\hline \multicolumn{1}{c}{ Metais } & Bloco 1 & Bloco 2 & Bloco 3 & Bloco 4 & Bloco 5 & Lim. Máx. (mg.L L $^{-1}$ ) \\
\hline Arsênio & n.d & n.d & n.d & n.d & n.d & 1,0 \\
Bário & n.d & n.d & n.d & n.d & n.d & 70,0 \\
Cádmio & n.d & n.d & n.d & n.d & n.d & 0,5 \\
Chumbo & n.d & n.d & n.d & n.d & n.d & 1,0 \\
Cromo & $1,18.10^{-3}$ & $2,62.10^{-3}$ & $3,13.10^{-3}$ & $1,41.10^{-3}$ & $2,27.10^{-3}$ & 5,0 \\
Mercúrio & n.d & n.d & n.d & n.d & n.d & 0,1 \\
Prata & n.d & n.d & n.d & n.d & n.d & 5,0 \\
Selênio & n.d & n.d & n.d & n.d & n.d & 5,0 \\
\hline
\end{tabular}

n.d: não detectado.

Tabela X - Concentração de metais do extrato solubilizado dos blocos cerâmicos.

[Table X-Concentration of metals in solubilised extract of ceramic blocks.]

\begin{tabular}{|c|c|c|c|c|c|c|}
\hline Metais & Bloco 1 & Bloco 2 & Bloco 3 & Bloco 4 & Bloco 5 & Lim. Máx. (mg.L-1) \\
\hline Alumínio & $9,9.10^{-4}$ & $1,24.10^{-3}$ & $1,48.10^{-3}$ & $9,9.10^{-4}$ & $1,50.10^{-3}$ & 0,2 \\
\hline Arsênio & n.d & n.d & n.d & n.d & n.d & 0,01 \\
\hline Bário & n.d & n.d & n.d & n.d & n.d & 0,7 \\
\hline Cádmio & n.d & n.d & n.d & n.d & n.d & 0,005 \\
\hline Chumbo & n.d & n.d & n.d & n.d & n.d & 0,01 \\
\hline Cobre & $2,2.10^{-3}$ & $1,2.10^{-3}$ & $3,2.10^{-3}$ & $1,6.10^{-3}$ & $3,5 \cdot 10^{-3}$ & 2,0 \\
\hline Cromo & $1,25.10^{-3}$ & $6,82 \cdot 10^{-3}$ & $9,57 \cdot 10^{-3}$ & $2,11 \cdot 10^{-3}$ & $3,79 \cdot 10^{-3}$ & 0,05 \\
\hline Ferro & n.d & n.d & n.d & n.d & n.d & 0,3 \\
\hline Manganês & $1,83.10^{-3}$ & $2,05.10^{-3}$ & $2,39.10^{-3}$ & $8,78.10^{-3}$ & $2,53.10^{-3}$ & 0,1 \\
\hline Mercúrio & n.d & n.d & n.d & n.d & n.d & 0,001 \\
\hline Prata & n.d & n.d & n.d & n.d & n.d & 0,05 \\
\hline Sódio & 7,064 & 7,012 & 6,956 & 7,099 & 7,121 & 200,0 \\
\hline Zinco & $1,3.10^{-3}$ & $1,5.10^{-3}$ & $2,0.10^{-3}$ & $1,7.10^{-3}$ & $2,0.10^{-3}$ & 5,0 \\
\hline Selênio & n.d & n.d & n.d & n.d & n.d & 0,01 \\
\hline
\end{tabular}

No ensaio mecânico verificou-se a capacidade de carga que os blocos cerâmicos suportavam, quando submetidos às forças exercidas perpendicularmente sobre suas faces opostas, determinando se as amostras ofereciam resistência mecânica adequada, simulando a pressão exercida pelo peso da construção sobre os blocos. Para os ensaios mecânicos das amostras, foram obedecidos os procedimentos descritos na norma NBR 15270-3:2005 da ABNT. De acordo com a norma, os blocos cerâmicos de vedação devem atender ao requisito mínimo de $1,5 \mathrm{MPa}$.

Na Tabela VII estão apresentados os resultados da resistência mecânica dos blocos cerâmicos de vedação.

Analisando a Tabela VII, verificou-se que os blocos cerâmicos fabricados com as argilas 2 e 3 ficaram acima do limite mínimo estabelecido por norma, que é de 1,5 $\mathrm{MPa}$. Os blocos fabricados com argilas 1 e 4 ficaram no limite especificado pela norma $(1,5 \mathrm{MPa})$, atendendo às especificações da ABNT NBR 15270-3:2005, exceção feita aos blocos fabricados com a argila 5 . O excesso de areia na massa cerâmica reduz a coesão entre as partículas da estrutura cristalina do bloco, reduzindo também a plasticidade e a retração da massa cerâmica quando umidificada, tornando o bloco mais frágil [2]. Os blocos fabricados com a argila 5 não atenderam o limite mínimo para a resistência dos blocos cerâmicos por razão do excesso da fração areia em sua composição (32\% de areia fina e 5\% de areia grossa), observado na Tabela $\mathrm{V}$ de análise granulométrica. A argila 3 apresentada grande parte da sua composição da argila bruta refere-se à fração argila (58\% dado da Tabela V), ou seja, trata-se de um material com alta capacidade de coesão, contendo principalmente partículas da fração argila e silte, que são preponderantes para formação de rigidez do bloco durante sua queima em forno, aumentando consequentemente a resistência do bloco, o que foi verificado no ensaio mecânico. Assim, os blocos fabricados com a argila 3 apresentam melhores resultados de resistência a compressão quando comparados com os demais blocos de diferentes argilas. A matéria orgânica também 
pode influenciar na qualidade final dos blocos cerâmicos. A importância da quantificação de matéria orgânica deve-se ao processo de queima dos blocos, ocasionando a volatilização da mesma, causando, desta forma, perda de massa, formação de poros ou blocos com baixa densidade. O objetivo da determinação do índice de absorção de água é a verificação da porcentagem de água absorvida no período de $24 \mathrm{~h}$, à temperatura ambiente, e está diretamente relacionada com o índice de vazios da massa estrutural do bloco cerâmico, isto é, quanto maior a quantidade de água absorvida, maior a porosidade existente na massa cerâmica. De acordo com norma NBR 15270-3:2005 da ABNT, o índice de absorção de água não deve ser inferior a $8 \%$, nem superior a $22 \%$.

A Tabela VIII apresenta os resultados dos ensaios de absorção de água dos blocos cerâmicos a fim de verificar o atendimento ou não das normas vigentes.

Comparando os resultados da Tabela VIII com os valores indicados na norma para blocos cerâmicos de vedação (absorção entre 8 e 22\%), verifica-se que todas os blocos atendem as especificações.

De acordo com INMETRO (2006) [19], paredes de blocos cerâmicos de vedação com alta absorção de água, apresentam problemas na aderência da argamassa de reboco, pois a água existente na composição da argamassa é absorvida, resultando em uma massa seca sem poder de fixação. Apesar de fatores como quantidade da fração argila e matéria orgânica nas argilas, influenciaram as propriedades de absorção de água dos blocos cerâmicos, no presente trabalho este parâmetro não foi influenciado significativamente pelo tipo de argila utilizado na fabricação dos blocos cerâmicos de vedação. Todos os blocos cerâmicos fabricados apresentaram absorção de água dentro dos limites estabelecidos na NBR 15270-3:2005 da ABNT.

A caracterização dos blocos cerâmicos referentes às análises de metais foi feita por meio da determinação de suas características tóxicas, a partir das análises dos extratos lixiviados [11] e solubilizados [12], conforme apresentado nas Tabelas IX e X, respectivamente.

Os resultados dos testes de análise química mostraram que as concentrações dos metais nos extratos lixiviados e solubilizados dos blocos cerâmicos estão abaixo dos limites estabelecidos na norma NBR 10004:2004 [20]. Esses resultados demonstraram que os elementos químicos contidos no lodo têxtil, foram incorporados na massa cerâmica e permanecerão imobilizados no material cerâmico, sem haver prejuízos ou riscos de futura contaminação do solo durante a sua vida útil. Deve-se fazer uma ressalva neste ponto, porque o chumbo tem uma elevada pressão de vapor e baixa temperatura de fusão, o que pode fazer com que seja eliminado durante a queima, assim ele pode ter sido liberado para o ambiente e não ter ficado aprisionado na matriz. Dessa forma, verifica-se que as diferentes argilas analisadas no presente trabalho podem ser utilizadas na confecção de blocos cerâmicos com do lodo têxtil, a partir do encapsulamento do resíduo junto à matriz sólida, evitando a lixiviação ou solubilização dos elementos constituintes do resíduo, considerados nocivos ao ambiente. Os resultados dessas interações são sólidos não-perigosos ou menos perigosos que o resíduo original. Para o caso da região de Maringá, isto se torna uma boa alternativa de disposição destes resíduos uma vez que não há aterros industriais na região e a proximidade das jazidas de argilas cerâmicas, aumentariam a variabilidade de argilas, viabilizando a produção de blocos cerâmicos e minimizando o impacto ambiental gerado pelos resíduos industriais.

\section{CONCLUSÕES}

Os diferentes tipos de argilas estudadas no presente trabalho influenciaram diretamente o comportamento dos blocos cerâmicos, atuando em suas características mecânicas, físicas e estruturais. As argilas analisadas apresentaram limites de plasticidade dentro da faixa indicada para cerâmica vermelha e que são constituídas basicamente por quartzo, hematita, caulinita e carbanilida. Analisando as características mecânicas dos blocos cerâmicos, verificouse que os blocos fabricados com as argilas 2 e 3 ficaram acima do limite mínimo especificado pela norma, enquanto que os blocos fabricados com argilas 1 e 4 ficaram no limite da norma, exceção feita aos blocos fabricados com a argila 5, que não alcançaram tal limite mínimo de 1,5 MPa por razão do excesso da fração areia em sua composição. Nos ensaios de absorção de água, todas as amostras de blocos cerâmicos atenderam as especificações exigidas por norma. Nos ensaios relacionados às características tóxicas referentes aos procedimentos de lixiviação e solubilização, os resultados mostraram que as concentrações de metais nos extratos lixiviados e solubilizados dos blocos cerâmicos, estavam abaixo dos limites definidos pela norma NBR 10004:2004. O processo de solidificação/estabilização mostrou-se como uma alternativa eficaz de disposição do resíduo, proporcionando vantagens tanto para a indústria de cerâmica vermelha, minimizando a utilização da argila como matéria-prima, sem comprometer a qualidade do bloco cerâmico produzido, como também ao ambiente, reduzindo o impacto causado pelo resíduo caso fosse disposto no solo sem tratamento prévio.

\section{REFERÊNCIAS}

[1] R. S. Macedo, R. R. Menezes, G. A. Neves, H. C. Ferreira, Estudo de argilas usadas em cerâmica vermelha, Cerâmica 54 (2008) 411.

[2] O. T. Kaminata, "Aproveitamento do lodo gerado no tratamento de efluente da indústria de lavanderia têxtil na produção de bloco de cerâmica vermelha", Diss. Mestrado, DEC-UEM (2008) 50.

[3] R. Malviya, R. Chaudhary, Factors affecting hazardous waste solidification/stabilization: A review, J. Hazardous Mater. B137 (2006) 267-276.

[4] E. C. C. Prim, "Valorização do lodo da indústria têxtil como material de construção civil utilizando a técnica de solidificação/estabilização com cimento" In: XXVI Cong. Interam. Ing. Sanit. Amb. - Aidis (1997), disponível em: 
$<$ http://www.cepis.org.pe/bvsaidis/resisoli/peru/brares172. pdf>, acesso em 19 jul. 2014.

[5] E. J. Kiehl, "Manual de Edafologia: Relação soloplanta", Ed. Agronômica Ceres, S. Paulo, SP (1985) 262.

[6] APHA. "Standard Methods for the Examination of Water \& Wastewater", Método $4500-\mathrm{H}^{+} \mathrm{B}, 21^{\mathrm{a}}$ ed. Washington, EUA (2005).

[7] Associação Brasileira de Normas Técnicas, NBR 7181, "Solo - Análise granulométrica", Rio de Janeiro, RJ (1984). [8] Associação Brasileira de Normas Técnicas, NBR 7180, "Determinação do limite de plasticidade - método de ensaio", Rio de Janeiro, RJ (1984).

[9] Associação Brasileira de Normas Técnicas, NBR 6459, "Determinação do limite de liquidez - método de ensaio", Rio de Janeiro, RJ (1984).

[10] EMBRAPA - Serviço nacional de levantamento e conservação de solos, "Manual de métodos de análise de solos", Ed. SNLCS, Rio de Janeiro-RJ, (1979).

[11] Associação Brasileira de Normas Técnicas, NBR 10005, "Procedimento para obtenção de extrato lixiviado de resíduos sólidos", Rio de Janeiro, RJ (2004).

[12] Associação Brasileira de Normas Técnicas, NBR 10006, "Procedimento para obtenção de extrato solubilizado de resíduos sólidos", Rio de Janeiro, RJ (2004).

[13] Associação Brasileira de Normas Técnicas, NBR 15270-3, "Blocos cerâmicos para alvenaria estrutural e de vedação - método de ensaio", Rio de Janeiro, RJ (2005).

[14] CETESB - "Resíduos Sólidos Industriais", Trabalho elaborado pelo corpo técnico da CETESB (1993).

[15] G. W. Thomas, "Soil pH and Soil Acidity", in: Methods of Soil Analysis. Part 3. Chemical Methods, Soil Science Soc. America, Book Series 5 (1996) 475-490.

[16] P. S. Santos, "Ciência e Tecnologia de Argilas", Ed. Edgard Blucher Ltda., S. Paulo, SP, 1 (1989).

[17] L. F. A. Campos, R. S. Macedo, P. K. Kiyohara, H. C. Ferreira, Características de plasticidade de argilas para uso em cerâmica vermelha ou estrutural, Cerâmica 45 (1999) 295.

[18] V. S. G. Renedo, "Dinámica y mecánica de suelos", Madrid: Ed. Agrotécnicas S.L. (1996) 426.

[19] INMETRO - "Bloco cerâmico de alvenaria Regulamento de avaliação de conformidade", Portaria 013, 25/01/2006.

[20] Associação Brasileira de Normas Técnicas, NBR 10004, "Resíduos Sólidos", Rio de Janeiro, RJ (2004).

(Rec.01/09/2014, Ac. 31/01/2015) 